Roselló Verdeguer, J. (2020): Trabajando con lenguajes de especialidad: una mirada al léxico del español para los negocios a través de los libros de economía y empresa. Cultura, Lenguaje y Representación, Vol. XXIII, 151-168

ISSN $1697-7750 \cdot$ e-ISSN 2340-4981

DOI: http://dx.doi.org/10.6035/clr.2020.23.10

\title{
Trabajando con lenguajes de especialidad: una mirada al léxico del español para los negocios a través de los libros de economía y empresa
}

Working with Specialised Languages: A Look at the Spanish Lexicon for Business through Economics and Business Books

RESUMEN: El léxico es un factor fundamental en la enseñanza de una lengua, y todavía adquiere más importancia cuando se trata de lenguajes de especialidad. Desarrollamos aquí una propuesta en la que se pretende enseñar léxico de los negocios tomando como punto de partida los títulos de libros del ámbito económico y empresarial. La crisis económica vivida en los últimos años ha generalizado muchos de estos términos, lo que ha convertido a este tipo de léxico en un material interesante de estudio, ya que permite observar, por un lado, sus características como lenguaje técnico (afijos de origen culto, siglas, anglicismos...) $\mathrm{y}$, por otro, su tendencia hacia lo coloquial y popular (metáforas, juegos de palabras...).

Palabras clave: léxico, lenguajes específicos, crisis económica, aprendizaje.

ABSTRACT: The lexicon is an essential element in the teaching of a language and acquires more importance in the so-called specialised languages. The aim of this paper is to show a practical experience in which we teach business lexicon taking into account book titles in the economic and business field. The economic crisis in recent years has generalised many of these terms and has transformed this type of lexicon into an interesting study material, because it allows us to observe, on the one hand, its characteristics as technical language (affixes of cultivated origin, acronyms, anglicisms...), and, on the other hand, its tendency towards the colloquial and popular (metaphors, play on words...).

Key words: Lexicon, specialised languages, economic crisis, learning. 


\section{INTRODUCCIÓN}

El léxico, entendido como el conjunto de vocablos, voces o palabras que integra el sistema de la lengua (Gómez Devís, 2003), constituye una de las piezas fundamentales del desarrollo de las destrezas y habilidades comunicativas. La idea del léxico como eje fundamental en el aprendizaje de la lengua extranjera o lengua segunda comienza a tomar fuerza a mediados de los años setenta, cuando se ponen en marcha los enfoques comunicativos, los cuales conjugan los métodos de la lingüística funcional británica con la sociolingüística estadounidense y la filosofía del lenguaje o pragmalingüística (Calero Vaquera, 2018). Pero, sin duda, es el enfoque léxico de Lewis $(1993,2000)$ el que más trascendencia le otorga, hasta el punto de redefinir el concepto de gramática, que ahora pasa a un segundo plano, y considerar la secuencia léxica o lexia el componente esencial de una lengua. Así pues, Lewis abre un cambio de paradigma en la enseñanza de lenguas extranjeras, pues concibe la lengua como un conjunto de piezas léxicas que se relacionan entre sí a través de unas estructuras gramaticales en lugar de lo contrario, como se había considerado habitualmente, esto es, un conjunto de estructuras sintácticas en la que se insertan las unidades léxicas (Vidiella Andreu, 2012).

Por otro lado, el léxico, que es un elemento clave para el desarrollo comunicativo, debe ocupar un lugar central en la programación de un curso de lengua extranjera, y en dicha programación se hace necesario diseñar actividades que incluyan morfología léxica (prefijos, sufijos...), unidades léxicas (palabras) y los denominados chunks, esto es, segmentos léxicos de extensión superior a la palabra, donde tendrían cabida las unidades fraseológicas.

Son muchos los modelos que se han llevado a cabo para una correcta planificación del léxico en el aula. En este sentido, es interesante la propuesta de Gómez Molina (1997), que, tomando como referencia el triángulo semántico de Ullman (1965), diseña un modelo didáctico en donde, a través de una palabra clave, se organiza toda una serie de relaciones (referentes, lexicogénesis, relaciones sémicas, agrupaciones conceptuales, niveles de uso, expresiones hechas y gramaticalización). Aunque no todas las palabras clave o estímulo permiten el desarrollo completo de estos siete elementos (un hetpágono), «lo importante es procurar el diseño de las tareas más idóneas según las posibilidades de la unidad léxica objeto de estudio» (Gómez Molina, 1997: 77).

También Higueras (2017: 16-19) insiste en la enseñanza del léxico y, como cree que se le da poca importancia a su enseñanza en cursos de posgrado, establece una lista de aspectos relevantes para la formación de profesores de ELE, entre los que destacan:

a) Detectar y atender las necesidades léxicas del alumnado.

b) Saber presentar el léxico (tanto palabras aisladas como unidades léxicas) de forma contextualizada.

c) Enseñar bloques o chunks.

d) Crear oportunidades para el uso del léxico, es decir, que aunque se realicen otras actividades, no se pierda de vista el elemento léxico.

e) Aplicar criterios para decidir qué léxico enseñar, teniendo en cuenta el contexto y las necesidades de los alumnos.

f) Instruir al alumnado en el uso de diccionarios.

g) Saber explicar la cultura a través del léxico

$\mathrm{Si}$ todos estos elementos han de tenerse en cuenta en un curso genérico de español como lengua extranjera, con igual o más motivo tienen que estar presentes en aquellos cursos de lengua destinados a fines específicos, puesto que en este contexto la 
comunicación eficaz va a depender, en gran parte, del conocimiento y uso de este léxico específico (económico, jurídico, médico...).

A la hora de abordar las lenguas para fines específicos y su didáctica, algunos autores realizan precisiones terminológicas y distinguen entre «lengua para fines específicos» y «lengua de especialidad». Así, Martín Peris et alii (2011: 2) señalan que la primera, de origen inglés, surge del contexto de la enseñanza de lenguas y su objeto de estudio es la L2, mientras que la segunda se inserta en el contexto de la lingüística descriptiva y analiza una determinada variedad de la lengua. Por consiguiente, las lenguas para fines específicos tienen objetivos más amplios y se interesan también por los usos sociales específicos de la lengua, por lo que integrarían otros componentes, como el sociocultural.

\section{EL LENGUAJE ECONÓMICO Y EMPRESARIAL: ENTRE LO TÉCNICO Y LO DIVULGATIVO}

Consideramos el lenguaje económico o de los negocios como una lengua de especialidad. Martínez Egido (2009: 172) lo como una «lengua de especialidad económica caracterizada por un lenguaje que mezcla lo técnico y lo divulgativo, que no siempre se utiliza entre expertos que tiene como finalidad la comunicación sobre temas económicos entre los ciudadanos».

Como veremos después con más detalle, esta definición sitúa al lenguaje económico en la frontera entre lo técnico y lo divulgativo, por lo que se va a situar en un terreno muy interesante para el análisis. Por un lado, participa de los mecanismos de formación de palabras propios del lenguaje técnico, con raíces o afijos tomados de lenguas clásicas o provenientes de términos del inglés que los envuelven de un aparente prestigio, y, por otro, va a presentar un léxico mucho menos específico con el que llegar a un público más amplio a través de juegos de palabras, dobles sentidos y elementos ideológicos. Es lo que hemos observado en muchos títulos de libros de economía y empresa, los cuales constituyen el corpus de este trabajo, y sobre los que trataremos en los siguientes puntos.

Cuando estalló la crisis en España, muchos medios de comunicación generalista empezaron a emplear términos que hasta entonces se habían circunscrito al ámbito económico y empresarial: rescate financiero, prima de riesgo, deuda pública, índice bursátil, etc. Todos estos términos no tardaron en pasar a la ciudadanía, que comenzó a usarlos con la misma naturalidad con que se utilizan otros de carácter político o futbolístico. Fue, según los expertos, uno de los efectos de la crisis económica: de súbito, una materia temida por muchos se convertía en tema de conversación cotidiana. Además, el conocimiento sobre temas económicos se tradujo en una necesidad social demandada por muchos grupos sociales, por lo que la competencia lingüística en este ámbito adquirió gran importancia. Los libros y el mundo editorial también se contagiaron de esta tendencia y en poco tiempo las librerías se vieron inundadas por títulos que hacían referencia a la economía, la empresa, los mercados y la crisis. Pero, en esta ocasión, no eran libros destinados solo a especialistas sino también a otro tipo de gente que, por un lado, intentaba entender qué había ocurrido y, por otro, se sentía atraída por todos esos gurús que salían en los platós televisivos y en las tertulias radiofónicas ${ }^{1}$.

\footnotetext{
${ }^{1}$ A este respecto, Vila Rubio distingue entre lo que se considera propiamente léxico económico y el léxico financiero y del comercio y de la industria. Tomando como punto de partida la distinción realizada por Alcaraz y Hughes (1996) para el inglés en su Diccionario de términos económicos y comerciales, esta autora considera que el léxico económico mantiene en su terminología un nivel más formal y académico,
} 
Así pues, a los libros especializados en economía y gestión, que ya tenían su público en profesionales y estudiantes del sector, se añadieron otros de divulgación, que tuvieron que adaptar sus títulos a ese sector de público recién llegado: Economía de andar por casa, El economista en pijama, Ten peor coche que tu vecino, etc. Los editores, conscientes de este auge de la literatura económica, contactaron con periodistas dedicados a la información económica, conscientes de que ellos eran las personas idóneas, ya que llevaban muchos años tratando de acercar un tema tan complejo como el funcionamiento de la economía al gran público. En estos casos, lo primero que el escritor se plantea es el lenguaje que debe utilizar, mucho más sencillo y accesible, $\mathrm{y}$, antes de todo, el título que debe poner a su trabajo, ya que esto, a buen seguro, acercará o alejará al posible lector. De ahí que los títulos y el léxico utilizado en ellos sea una buena materia para el análisis.

En el trabajo realizado con alumnos y alumnas del curso de «Español para los negocios», se les mostró, en primer término, una serie de títulos de libros relacionados con la economía y la empresa con el objeto de explicar la actividad que se iba a llevar a cabo. Los objetivos generales en este primer acercamiento eran los siguientes:

a) Introducir el léxico habitual en este tipo de cursos (bolsa, emprendedor, economía, capital...), presentes en casi todos los títulos.

b) Fijarse en los elementos compositivos (prefijos, sufijos, siglas...) y los valores que aportan en la formación de palabras (desaceleración, revalorización, mileurista...).

c) Presencia de extranjerismos (anglicismos, sobre todo) en el léxico económico y reflexión sobre los valores ideológicos de tales términos.

d) Uso metafórico de términos (Piratas de lo público) y conocimientos culturales necesarios para la correcta interpretación de los títulos ( $L a$ economía en dos tardes).

e) Términos ambiguos o que presentan más de un significado: mercados, liberal, populista...

A partir de estas premisas, los alumnos, divididos en grupos, tenían que buscar títulos de libros y realizar los comentarios pertinentes de acuerdo con los objetivos planteados en el trabajo. Exponemos aquí los resultados obtenidos.

\section{LOS LIBROS DE ECONOMÍA Y EMPRESA}

A pesar de la gran variedad de recursos educativos existentes en el mercado y los avances que se han producido en los últimos años en el ámbito tecnológico, lo cierto es que el libro sigue constituyendo uno de los principales medios para transmitir el conocimiento, también en la enseñanza de idiomas. No hay que olvidar, como señala Hernández Navarro (2019: 109), que se aprende, fundamentalmente, leyendo y que «cuando los alumnos te preguntan que dónde has aprendido, que cómo se llega a conocer lo que conoces, solo tienes una respuesta: leyendo». Así pues, siempre es conveniente y necesaria la propuesta de lectura de libros adaptados a su nivel y sus fines. Para las clases de español de los negocios nosotros propusimos la búsqueda, tanto en internet como en librerías de la ciudad, de libros relacionados con la economía y la empresa. La primera labor consistía en fijarse en los títulos, pues de ellos se podría extraer mucho léxico relacionado con los temas objetos de estudio de la asignatura (Imagen 1)

utilizado principalmente en la comunicación universitaria, mientras que el léxico financiero y comercial presenta una mayor tendencia hacia lo coloquial y popular. 


\section{Imagen 1. Portadas de libros de economía y empresa}

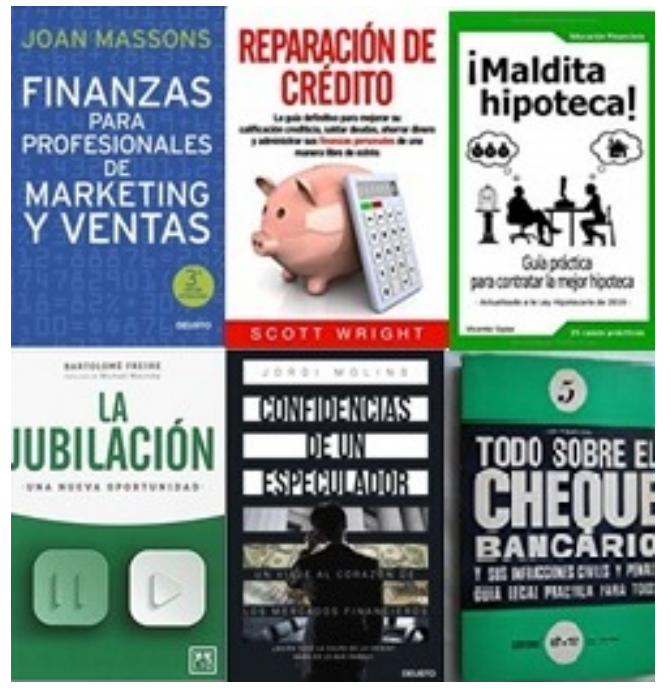

En la Tabla 1 se exponen algunos de los títulos recogidos para el trabajo ${ }^{2}$.

Tabla 1. Muestra de los libros utilizados

\begin{tabular}{|l|l|}
\hline \multicolumn{2}{|c|}{ LIBROS } \\
\hline -Invertir tus ahorros y multiplicar tu & -Crecer en franquicia \\
dinero & -Tu modelo de negocio \\
-Cómo entender los tipos de interés & -Inflación, paro y productividad. El caso \\
-Cómo invertir en fondos de inversión & español y europeo \\
-Reglamento del registro mercantil & -El emprendedor, o los accionistas, \\
-Reparación del crédito & crean empresas para producir ganancias, \\
-Todo sobre el cheque bancario & nunca para perder dinero \\
-Cuatro pilares de la inversión & -Eres liberal y no lo sabes \\
-Secretos para ganar en los mercados & -Análisis técnico de los mercados \\
alcistas y bajistas & financieros \\
-Nóminas y seguros sociales 2019 & -El engaño populista \\
-Gestionar el patrimonio en tiempos de & -Libertad de emprender \\
globalización & -¡Hoy voy a emprender! \\
-El libro de los emprendedores & -Crea tu propia empresa \\
-¿Por qué en 2017 volveremos a entrar & -Y tú, ¿qué marca eres? \\
en recesión? & -La espiral de la austeridad \\
-Confidencias de un especulador & -La jubilación \\
-Las finanzas en una sociedad justa & -Ganar en la bolsa es posible \\
-Reformas o declive & -¡Maldita hipoteca! \\
- Las dos próximas recesiones & -Crecer en franquicia \\
-Finanzas para profesionales de & -Tu modelo de negocio \\
marketing y ventas & -La burbuja emprendedora \\
& \\
\hline
\end{tabular}

Como vemos, todos estos títulos contienen léxico económico y aparecen en el $D L E$, tanto si se trata de unidades léxicas (ahorro, dinero, crédito, cheque, bancario, mercados, nóminas, emprendedor, recesión, finanzas, especulación, franquicia, negocio, inflación, paro, accionista, liberalismo, empresa, austeridad, hipoteca) como

\footnotetext{
${ }^{2}$ En el Anexo 1 se indican todos los libros utilizados, el autor y la editorial.
} 
si son unidades fraseológicas (tipos de interés, fondos de inversión, registro mercantil). La mayoría de ellas están recogidas como acepciones, sin ningún tipo de marca, como es el caso de ahorro, dinero, crédito, cheque, emprendedor, especulador, etc. y solo unas pocas llevan marcas diatécnicas, como es el caso de tipo: «Econ. Cantidad fija o porcentual que aplicada a la base imponible determinan la cuota tributaria», acción: «Econ. Título valor que representa una parte alícuota en el capital de una sociedad mercantil y que da derecho a una parte proporcional en el reparto de beneficios y a la cuota patrimonial correspondiente en la disolución de la sociedad», recesión: «Econ. Depresión de las actividades económicas en general que tiende a ser pasajera», o burbuja: «Econ. 'Proceso de fuerte subida en el precio de un activo, que genera expectativas de subidas futuras no exentas de riesgo». En el caso de bolsa, el DLE lo incluye como término homónimo, ya que en su sentido económico proviene del nombre de la familia Van der Bourse, en Brujas.

De igual modo, los títulos de los libros que contienen léxico económico nos han servido para analizar la morfología de las palabras. Los mecanismos morfológicos del discurso económico son propios de las lenguas de especialidad:

-Prefijación. Utilización de prefijos como des-, im- re- contra-, etc.: Desmotivados = improductivos (Las verdaderas razones de la falta de productividad); La desaceleración económica: las causas e implicaciones en los países desarrollados; La revalorización de las pequeñas y medianas empresas desde lo local; El contraataque liberal, etc. Abundan sobre todo los prefijos cultos, como macro-, tele-, hiper-, auto-: Neuropirámide, base del neuromarketing; Crítica del hipercapitalismo digital; Teletrabajo y neurotecnología, Autogestión para tiempos de crisis (Imagen 2).

\section{Imagen 2. Utilización de prefijos en títulos de libros de economía}

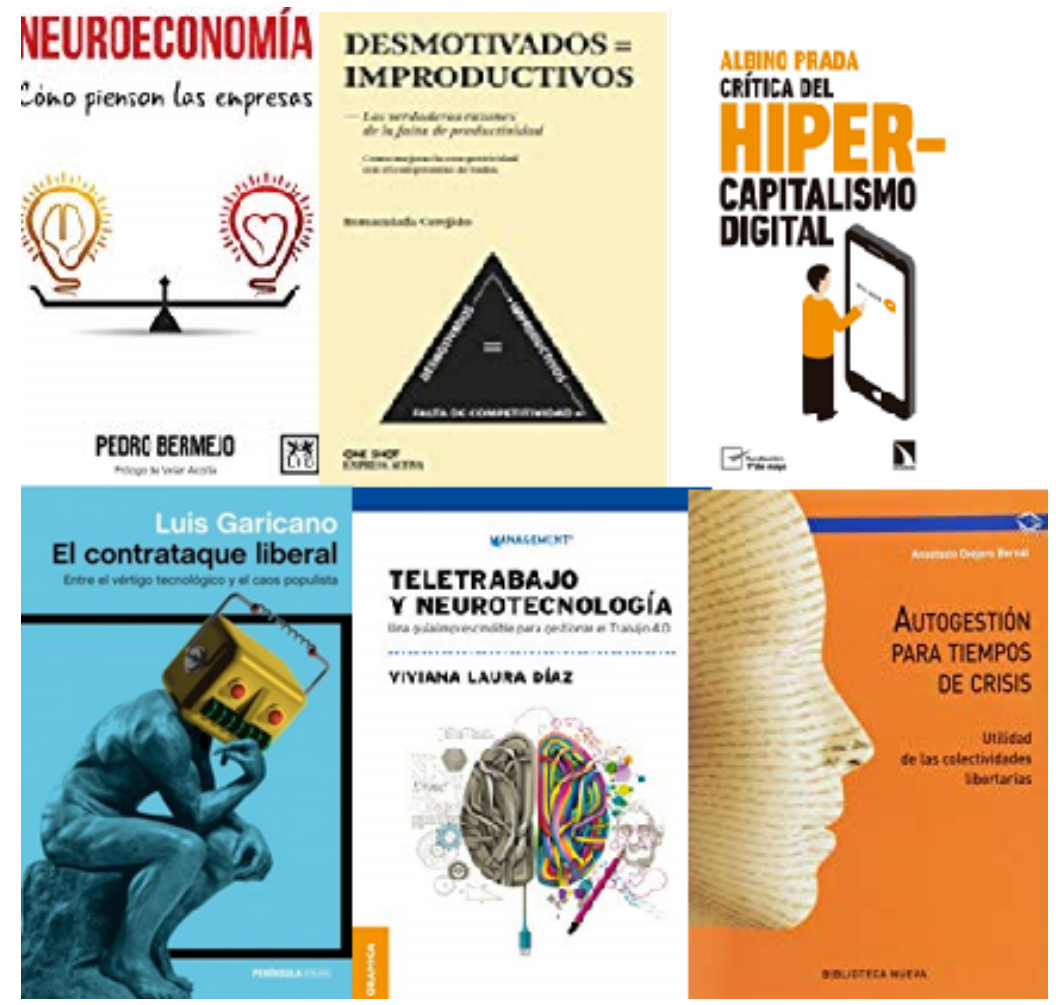


-Sufijos, algunos muy abundantes como -ismo (capitalismo, populismo, nacionalismo...), llegan a crear términos no admitidos en el diccionario pero que tienen gran productividad en la lengua, como es el caso de talentismo, en Del capitalismo al talentismo: claves para triunfar en la nueva era, en donde el autor vincula un sistema económico (capitalismo) con el talento. La productividad de este sufijo, como reconoce la NGLE (2009: 439), permite que se formen muchas palabras mediante este procedimiento: artepurismo, versolibrismo, tortuguismo, etc. También el afijo euro, utilizado como prefijo (eurobono, eurobarómetro) y como sufijo ha tenido gran relevancia en el léxico económico. De especial interés es el término mileurista, presente en numerosos libros (Mileuristas: retrato de la generación de los mil euros; Riqueza y bolsa para mileuristas: cómo alcanzar la libertad financiera mejorando tu economía; De mileurista a millonario). Con respecto a esta palabra, Álvarez de Miranda (2016: 24) señala que fue una lectora del diario El País, Carolina Alguacil, la que se sirvió de este término para referirse «a un vocablo designador del nuevo grupo social al que ella y sus compañeros pertenecían: los mileuristas». Más tarde, fueron los medios de comunicación los que la difundieron y hoy figura ya en el $D L E$ : «Dicho de una persona: que percibe un sueldo mensual que se sitúa en torno a mil euros y generalmente se considera por debajo de sus expectativas profesionales». En otros casos, como señala Rodríguez Gallardo (2016), la creación morfológica produce unidades léxicas anómalas, como es el caso de austericidio. La Fundéu señala que esta palabra aparece cada vez más con mayor frecuencia en las noticias económicas para aludir, con connotaciones negativas, a los efectos de las medidas de austeridad. Pero austericidio se refiere a 'matar de austeridad' y no es adecuado emplearla con el sentido de 'matar por exceso de austeridad' (Imagen 3).

Imagen 3. Sufijos en títulos de libros de economía

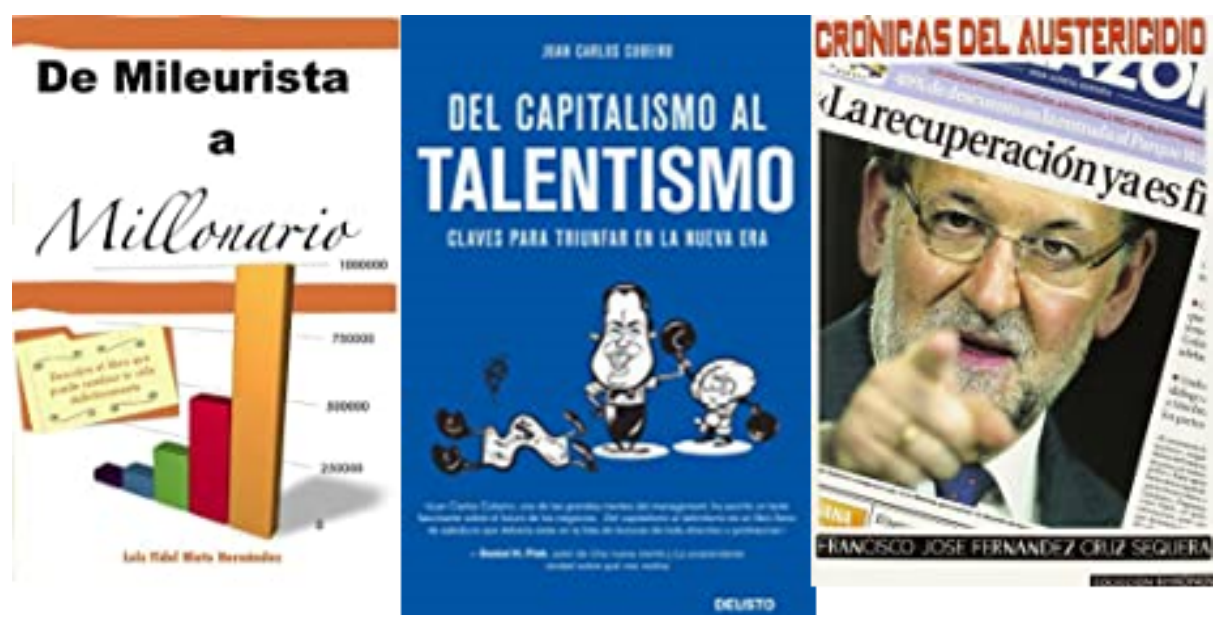

En los libros que estamos analizando sobre economía, empresa y finanzas es muy habitual también que se recurra a los anglicismos, las siglas y todo tipo de juegos de palabras. En realidad, como señala Romero Gualda (1993: 46), son peculiaridades léxicas que aparecen muy frecuentemente en los medios de comunicación. Por consiguiente, las técnicas utilizadas por estos no difieren demasiado de las empleadas por los editores y escritores, muchos de los cuales, como hemos señalado al principio, también escriben en los diarios o participan en radio y televisión. 
Las siglas son, en principio, un mecanismo de economía del lenguaje, pero lo cierto es que se abusa de ellas, sobre todo en el lenguaje financiero y de los negocios. Además, muchas de ellas, provenientes del inglés, sustituyen a términos existentes en castellano porque enmascaran un supuesto prestigio. Es el caso de $C E O$, que sirve para definir a la persona que tiene la más alta responsabilidad dentro de una corporación, y que en España siempre ha sido designada como consejero delegado o director ejecutivo (Hablar como un CEO). Otras han sido lexicalizadas, como es el caso de pyme (Cómo gestionar una PYME y no morir en el intento), aparecen en el DLE como siglas, caso de $A D N$ (El ADN de la formación para directivos) o son muy habituales (Las TIC en la empresa turística). Pero también encontramos otras circunscritas al mundo empresarial y creadas con el fin de llamar la atención sobre el producto que ofrecen: $E l R O I$ (rendimiento de la inversión) del capital humano; G.E.R. Gestión Eficaz de Recompensas; El principio «Kicks» (Keep It Competitive, Stupid) (Imagen 4).

\section{Imagen 4. Utilización de siglas en títulos de libros de economía y empresa}

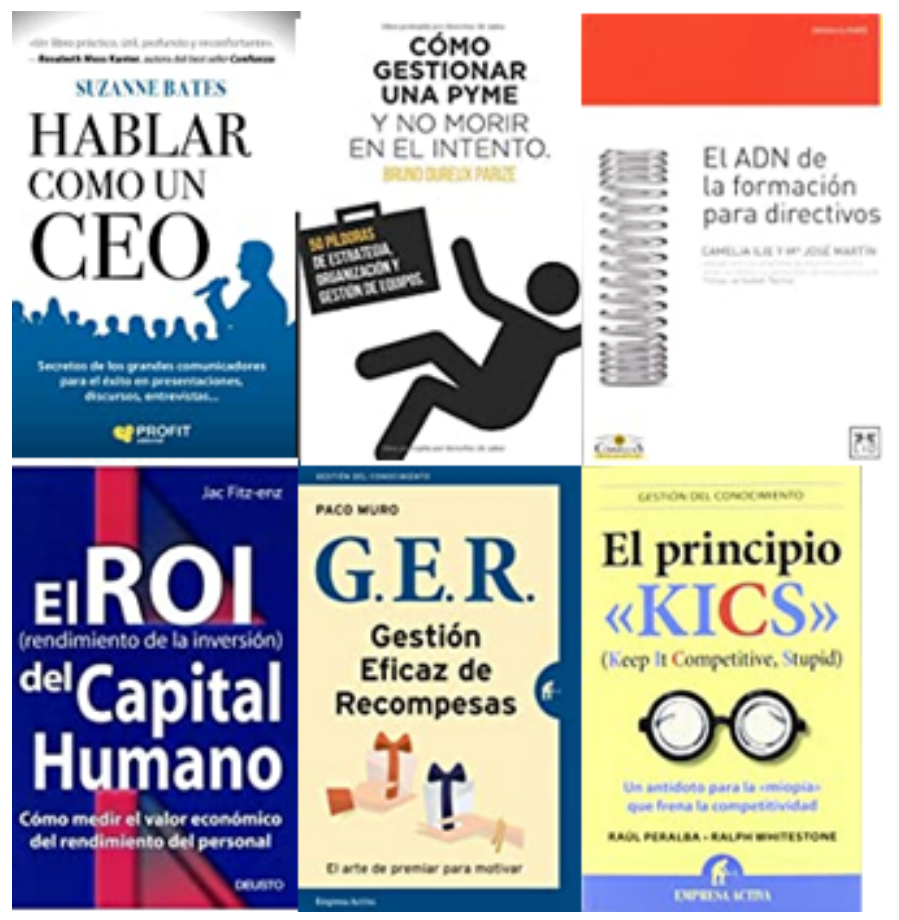

De igual modo, es indudable la presencia de extranjerismos provenientes del inglés en el español de los negocios. Son muchos los autores que se han ocupado del anglicismo (Lorenzo, 1996; Gómez Capuz, 2001; Medina López, 2004, etc.) y también son abundantes las reflexiones en los medios de comunicación (Lázaro Carreter fue uno de los primeros en sus famosas columnas de El dardo en la palabra, y ahora también Álex Grijelmo, entre otros). En el ámbito del español para los negocios se ha producido una verdadera invasión de palabras procedentes del inglés, muchas de ellas prescindibles, como es el caso de crack, sustituible por 'quiebra'; lobby, 'grupo de presión', o start-up, que podríamos traducir, siguiendo a Álex Grijelmo ${ }^{3}$, como 'empresa emergente'. Otros, ciertamente, resultan más difíciles de traducir, caso de dumping o holding, recogidas en el DLE, y que, como señala Barbero Andrés (2009), puede que se trate de anglicismos necesarios y que se incorporen para enriquecer nuestra lengua. Mánager es un término curioso, ya que se ha adaptado al español del

\footnotetext{
${ }^{3}$ «Las ‘start-ups' y las mariposas», El País, 28-5-2007.
} 
inglés (manager), pero manteniendo la pronunciación inglesa original, con $y$ [mánayer]. De ahí han surgido otros, como community manager. Por otra parte, no cabe duda de que el mantenimiento de muchos de estos términos obedece al prestigio de la lengua inglesa en el mundo y al modelo económico neoliberal (Rodríguez Gallardo, 2016: 72) (Imagen 5).

Imagen 5. Extranjerismos en títulos de libros sobre economía

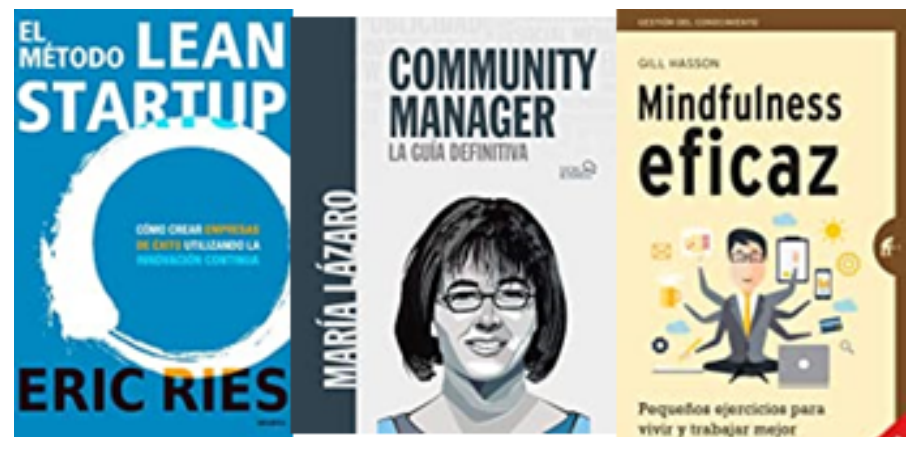

\section{ALGUNOS TÉRMINOS CONTROVERTIDOS: MERCADOS, LIBERAL, EMPRENDEDOR, POPULISMO}

Dentro de todos los títulos de libros que los estudiantes utilizaron para este trabajo, hemos observado que hay palabras que se repiten con mucha frecuencia. Una de ellas es mercado. No cabe duda de que este término guarda mucha relación con el mundo de los negocios, pero ¿qué significa exactamente mercado? En el sentido con que aquí lo tomamos, el mercado, tal como lo define el $D L E$ en su cuarta acepción, sería el «conjunto de actividades realizadas libremente por los agentes económicos sin intervención del público», o, en su quinta, el «conjunto de operaciones comerciales que afectan a un determinados sector de bienes». Sin embargo, como han puesto de manifiesto muchos especialistas, desde la crisis de la pasada década, los mercados han pasado a ser un concepto muy abstracto tras el cual se esconden no pocos intereses políticos y económicos. Este término, según Rodríguez Gallardo (2013), remite a una especie de fuerza impersonal y aséptica, como si no existiesen, aunque en realidad se sabe que nos estamos refiriendo a los bancos y a los grandes grupos inversores que compran la deuda, y también a los Estados y a las organizaciones económicas mundiales, a veces en colaboración con los actores privados, que fueron los que establecieron las reglas favorables para que se produjera el auge actual del mercado financiero.

Pero ¿qué nos dicen los libros analizados de este término? Hay títulos que son objetivos e intentan solo a aclarar el concepto y su funcionamiento (Nosotros, los mercados. Qué son, cómo funcionan y por qué resultan imprescindibles); otros, como El pequeño libro que aún vence al mercado, lleva el antetítulo de «Descubre la fórmula más rentable para invertir en bolsa», y el texto que se encuentra en su contraportada encierra la idea de que los mercados se comportan de una manera bastante críptica, pero que podemos encontrar fórmulas matemáticas sencillas para desentrañarlos y obtener beneficios. Sin embargo, la idea más extendida es la que hemos expuesto anteriormente de Rodríguez Gallardo y otros especialistas (por ejemplo, Laval y Darcot, 2009), que los ven como un entramado en donde es frecuente la connivencia con el poder y cobre especial importancia obtener información privilegiada para el lucro personal. Ejemplo 
de esto sería el libro Cómo acabar de una vez por todas con los mercados, que lleva el subtítulo de «Un viaje por el entramado de la casta, el dinero y el poder político». Recordemos que la casta era un concepto muy vinculado con los privilegios de los que gozaban muchos políticos (del partido popular y también del socialista, que se habían alternado en el poder durante los últimos años), de ahí que el subtítulo equipare casta, dinero y poder político (Imagen 6).

\section{Imagen 6. Utilización del término mercado en los títulos de libros}

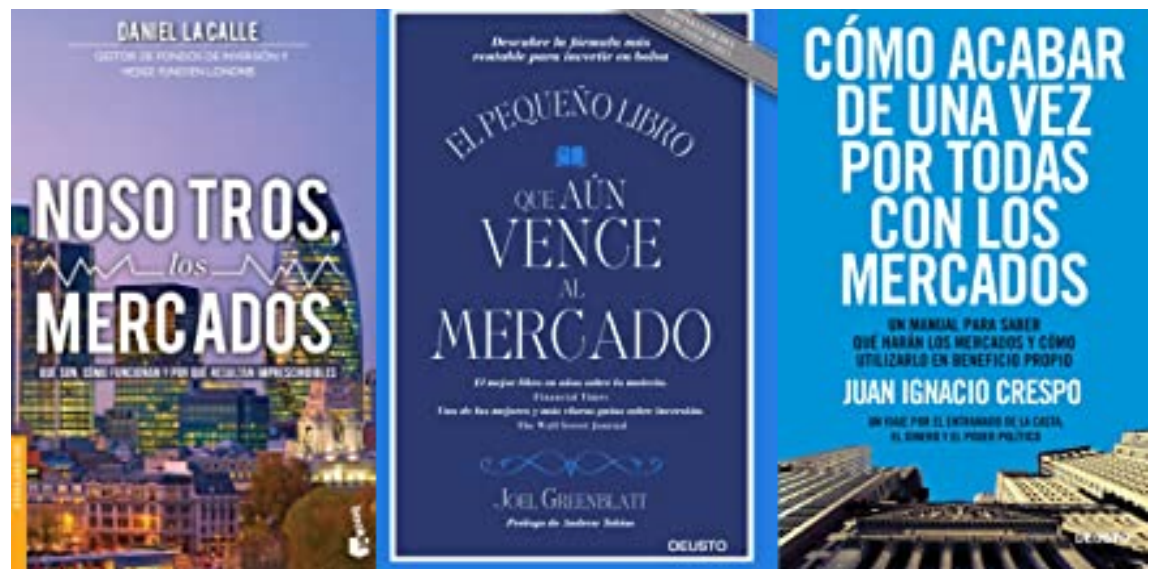

Liberal es otra de las palabras que aparece con frecuencia en los libros de economía y empresa, aunque es un término mucho más polisémico, ya que puede referirse a una doctrina política, a una persona alejada de modelos estrictos o rigurosos, a una profesión, etc. En términos económicos, podríamos decir que es la doctrina que promueve la libertad económica y está en contra de la intervención del Estado. Lo que se esconde detrás de muchos de los títulos analizados es que hay ciertos prejuicios detrás de esa palabra o de los que se definen como tales y que existe cierta necesidad de justificar las bondades de tal doctrina. Lo observamos en títulos como Eres liberal y no lo sabes, que lleva una pequeña entradilla en la portada que señala lo siguiente: «Un manifiesto europeo por el progreso y la convivencia frente al populismo y al nacionalismo». Queda claro, pues, que el liberalismo se asocia a palabras positivas (progreso y convivencia) frente a populismo y nacionalismo, que integrarían la cara opuesta al liberalismo. En El liberalismo no es pecado, el título ya nos previene contra los que atacan dicha doctrina, y las indicaciones de la portada («Obedeced: es por vuestro bien, por la igualdad. Callad: por la solidaridad, por el progreso. Pagad: por la cohesión, por la justicia social») ilustran que lo que se ha dicho tradicionalmente del liberalismo (el egoísmo, la insolidaridad, la riqueza desmedida de unos pocos) son conceptos erróneos. De igual modo, Un modelo realmente liberal (con el adverbio realmente resaltado en el título) señala en la portada que «Juan Ramón Rallo coordina el equipo que propone 33 reformas liberales para lograr una España más libre y próspera». Por tanto, también aquí se vincula liberalismo con palabras positivas como libertad y prosperidad (Imagen 7). 


\section{Imagen 7. Utilización del término liberal en títulos de libros}

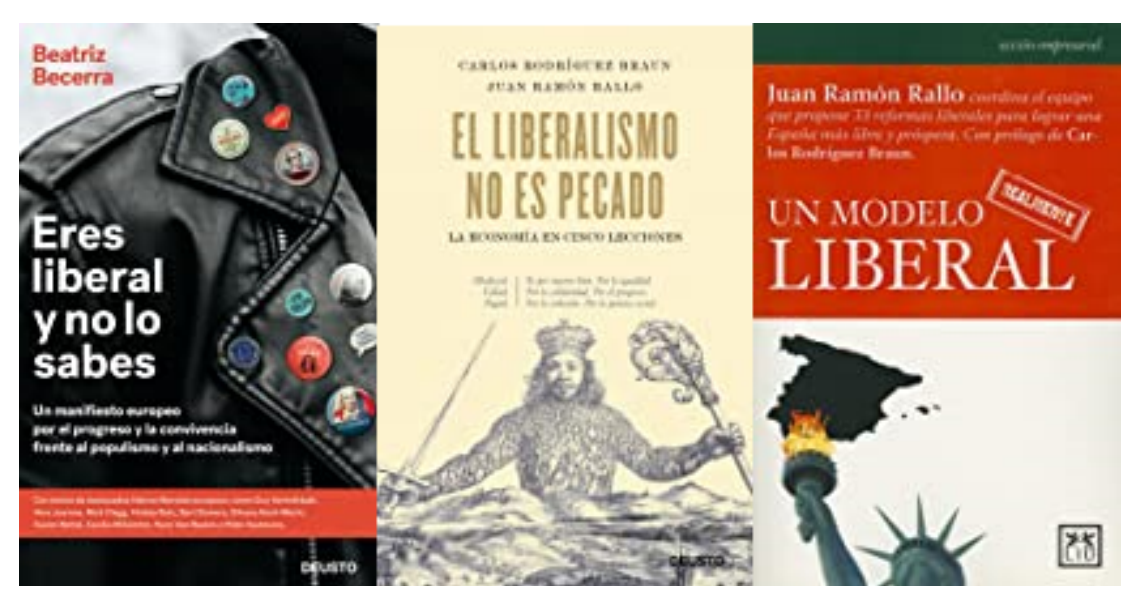

Por último, analizamos la palabra emprender y sus derivados (emprendedor, emprendimiento, etc.). Ciertamente, el término emprendedor ha sustituido a otro mucho más frecuente hace unos años para definir este menester, que era empresario. Es cierto que emprendedor tiene un significado más extenso, ya que puede aplicarse a muchos ámbitos, mientras que empresario se circunscribe a la empresa. El $D L E$ define este último como «Titular propietario o directivo de una industria, negocio o empresa», mientras que emprendedor es el «Que emprende (en el sentido de acometer y empezar una obra o negocio, 'especialmente si encierran dificultad o peligro') con resolución acciones o empresas innovadoras». Así pues, para emprender es necesario poseer ánimo, valor o arresto (no es otro el significado de 'resolución') e, igualmente, es necesario que el proyecto llevado a cabo encierre cierta dificultad o peligro.

Que emprender es cosa de valientes y comporta cierto riesgo puede advertirse en una gran parte de los títulos analizados (El libro negro del emprendedor: no digas que nunca te lo advirtieron; Destino emprender: el camino de dejar un trabajo seguro para aventurarse al emprendimiento; ¿Te atreves a innovar? Cómo emprender y no morir en el intento; Emprender a hostias...), pero la idea que se quiere transmitir en la mayoría de ocasiones es una imagen positiva del emprendedor vinculada al éxito y a la felicidad (Gente emprendedora, gente de calidad; Misión emprender: los 70 hábitos de los emprendedores de éxito; Sorbos de emprendimiento: sentir y pesar un proyecto de éxito; Loco por emprender: desafía las normas convencionales; El emprendedor digital: herramientas para triunfar en el mundo virtual con poco dinero...). En otras ocasiones se vincula el término a las artes (Emprendimiento hacia el 2020: una renovada perspectiva global del arte de crear empresas y sus artistas) o a la creación de un mundo más solidario (Emprendedores solidarios: Ignacio Álvarez de Mon presenta la historia de 26 personas que fundaron empresas para cambiar el mundo a mejor). También la ideología subyace en muchos de los títulos, ya que no es extraño ver este término vinculado a la economía liberal y de mercado. Así, el libro Libertad de emprender, lleva el siguiente antetítulo: «Daniel M. Mondejar defiende la necesidad de recuperar los valores del libre mercado para volver a la senda del crecimiento y el desarrollo económico» (Imagen 8). 


\section{Imagen 8. Utilización del término emprendedor y sus derivados}

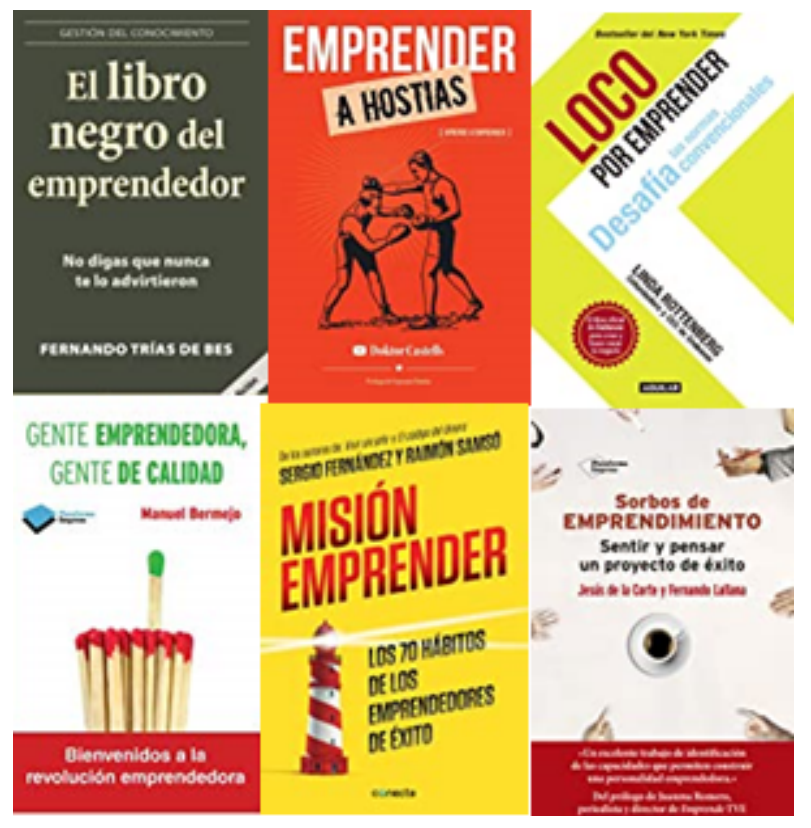

Finalmente, y aunque no sean términos estrictamente económicos, también aparecen con mucha frecuencia en los libros sobre la empresa y las finanzas las palabras populismo y líder. La primera, que fue elegida palabra del año 2016 por la Fundéu, era un término aparentemente neutro que, de hacer simple referencia a los intereses populares, se fue cargando de connotaciones negativas. Suele apelar, según dicho organismo, a las emociones de los ciudadanos y a ofertar soluciones simples a problemas complejos. Así, relacionado con el mundo económico, suele vincularse comúnmente al engaño y la ruina económica (La explosión populista; El engaño populista: por qué se arruinan nuestros países y cómo rescatarlos; El porqué de los populismos). Con respecto a la palabra líder (liderar, liderazgo...) suele tener, en cambio, connotaciones positivas: éxito, felicidad, perfección, etc. (Liderazgo, empresa y deporte; Madera de líder: la felicidad a través del liderazgo; Liderar en un mundo imperfecto o Ya eres líder, que lleva el siguiente antetítulo: «Nuria Sáez y Julián Trullén te ayudan a conectar con tu liderazgo natural para conseguir las metas que te propongas») (Imagen 9).

Imagen 9. Los términos populista y líder utilizados en los libros

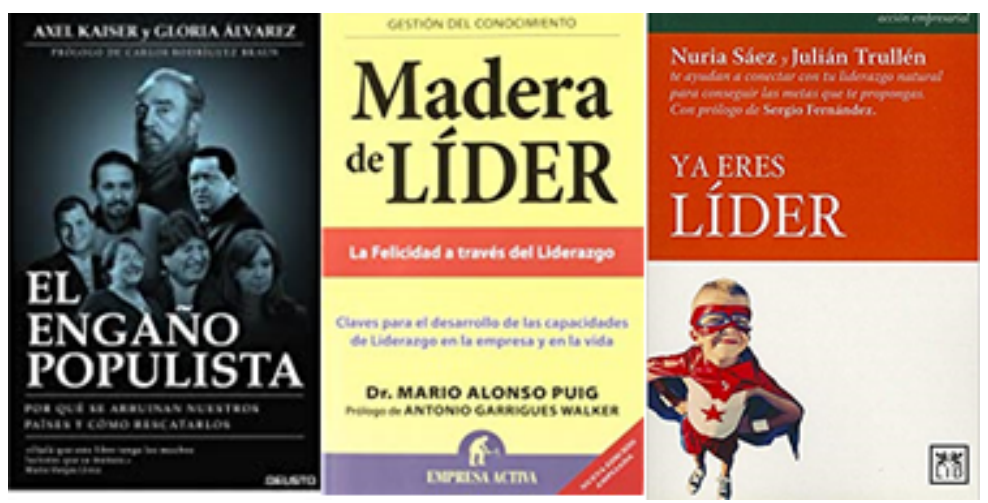




\section{JUEGOS DE PALABRAS Y TÉRMINOS METAFÓRICOS}

También nos hemos encontrado con títulos que realizan ingeniosos juegos de palabras que deben ser explicados a los estudiantes de español como lengua extranjera (Lo que no son cuentas son cuentos) o que necesitan de ciertas referencias culturales del país en el que se está viviendo (Soler-Espiauba, 2015). Es el caso de ¿Qué hace una persona como tú en una crisis como esta?, que remite a ¿Qué hace una chica como tú en un sitio como este?, una canción que el grupo musical Burning interpretó a finales de la década de los setenta del siglo pasado como parte de la banda sonora de la película del mismo título y con la que se solía entablar conversación o preguntar por gente que andaba más bien desubicada. El otro caso que comentamos es el libro de Jordi Sevilla, Economía en dos tardes: un manual para todos, incluidos presidentes del Gobierno, remite a una conversación privada, hecha pública por unos micrófonos no apagados, en la que el ministro de Economía Jordi Sevilla le dijo al entonces presidente del Gobierno Rodríguez Zapatero que la economía que él necesitaba aprender se podía explicar en un par de tardes (Imagen 10).

\section{Imagen 10. Juegos de palabras en los títulos de libros de economía}

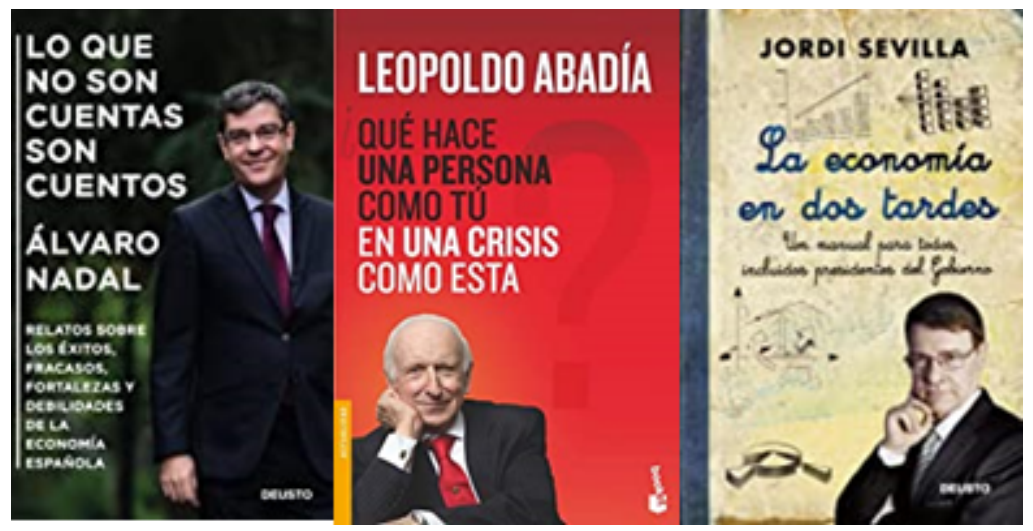

Si bien el lenguaje de la economía, como perteneciente al campo técnicocientífico, participa de las características de univocidad y monosemia de este tipo de léxico, también es altamente metafórico, debido, como se apuntó en los primeros epígrafes de este trabajo, a que la crisis generalizó muchos de estos términos financieros, que dejaron su estricto círculo económico y empresarial, y pasaron al lenguaje periodístico y, de ahí, también a la industria editorial. Como señala Cabré et alii (2008), la terminología económica tiende al dinamismo y a la polisemia, por lo que, como resulta habitual en cualquier tipo de lenguaje, se convierta también en metafórico y plurisignificativo. Sabemos que la metáfora ayuda a potenciar todo aquello que para nosotros es importante. Así, encontramos metáforas provenientes del mundo de la naturaleza (El archipiélago liberal, en donde archipiélago opera como un conjunto de individualidades que pueden llegar a asociarse y ser fuertes); otras provienen de la antropología, como tribu, que remite diferentes tipos de sociedad o de organización social (Las tribus liberales); de la guerra (El euro y la batalla de las ideas) o el recurso al viaje como inicio de una experiencia (Viaje a la libertad económica, libro que lleva el subtítulo de «Por qué el gasto esclaviza y la austeridad libera», que ya nos indica claramente la posición ideológica del autor). Por último, merece la pena detenerse el este título porque encierra gran contenido metafórico: Piratas de lo público: el 
neoliberalismo corsario al abordaje del estado del bienestar. Tenemos, por un lado, el término piratas, que remite a 'ladrón', en este caso de la cosa pública; y en el subtítulo vemos que el neoliberalismo es tildado de corsario, otro término metafórico del mundo de la piratería, y abordaje, más próximo a la locución 'al abordaje' con el sentido de tomar al asalto, en este caso el estado del bienestar (Imagen 11).

\section{Imagen 11. Utilización de términos metafóricos en títulos de libros}

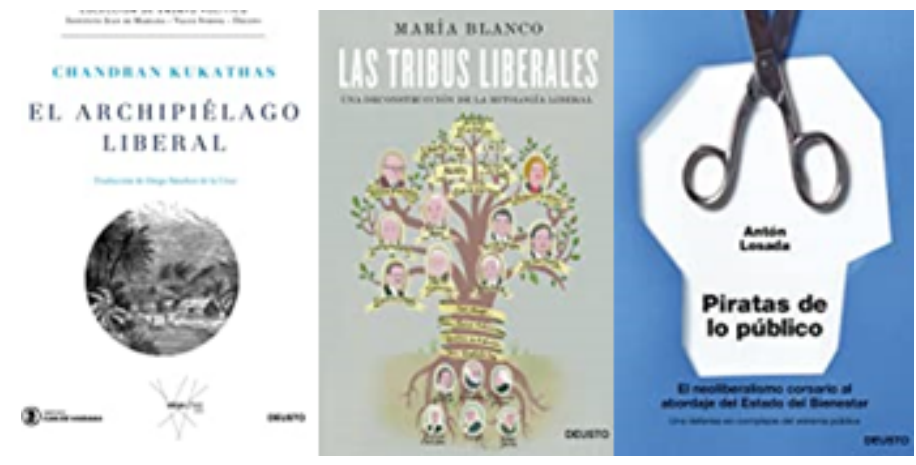

\section{CONCLUSIONES}

Así pues, hemos visto que los títulos de los libros de economía y empresa contienen un material muy interesante para diseñar actividades didácticas destinadas a enseñar léxico en un curso de español para los negocios. De ahí este primer acercamiento que realizamos, en el que solo se pretendía que los estudiantes se familiarizaran con la abundante bibliografía existente y extrajeran unas nociones básicas sobre la formación del léxico económico y otras consideraciones relacionadas con el componente semántico y cultural. Es nuestro propósito continuar con este trabajo diseñando actividades más precisas y profundizando sobre las ya realizadas. De momento, hemos visto que este tipo de léxico participa de los procesos de formación de palabras típicos del lenguaje técnico-científico, con abundancia de prefijos cultos (hiper-, tele- o neuro- en neuroeconomía, por ejemplo), sumados a otros afijos de tipo general (-izar o -miento, en emprendimiento), compuestos sintagmáticos propios del lenguaje económico (poder adquisitivo, renta básica, fondos de inversión), abundancia de siglas (IRPF, IVA, INEM. FMI) y anglicismos (coach, startup, networking), etc. Por otro lado, con la crisis económica vivida en España (y otros lugares de Europa y del mundo) a partir de 2008 se generalizaron muchos de los términos que hasta entonces estaban restringidos a estudiantes y expertos en economía. La prensa, la radio, la televisión y la industria editorial comenzaron a difundir este tipo de vocabulario especializado y a aproximarlo al lenguaje periodístico, de ahí que también se pudieran ver en muchos títulos de libros expresiones metafóricas (Viaje a la libertad económica), ironías (Economía para no dejarse engañar por economistas), juegos de palabras (Lo que no son cuentas son cuentos) e incluso creaciones léxicas ingeniosas (Rockvolución empresarial).

\section{REFERENCIAS BIBLIOGRÁFICAS}

Alcaraz, Enrique y Brian Hughes.1996. Diccionario de términos económicos, financieros y comerciales. Barcelona: Ariel.

Álvarez de Miranda, Pedro. 2016. Más que palabras. Barcelona: Galaxia Gutenberg. 
Barbero Andrés, Javier. 2009. «El español de los negocios y el inglés: convergencias y divergencias». En XX Congreso Internacional de ASELE. El español en contextos especificos: enseñanza e investigación, vol. I, ed. Agustín Vera Luján e Inmaculada Martínez Martínez. Salamanca: Funcación Comillas, pp. 269-285.

Battaner, Paz y Carmen López. 2019. Introducción al léxico, componente transversal de la lengua. Madrid: Cátedra.

Cabré, Maria Teresa et al. 2008. «Literalidad y dinamicidad en el discurso económico». VI Simposio Internacional de Terminología. Barcelona: Documenta Universitaria.

Calero Vaquera, M. ${ }^{a}$ Luisa. 2018. «Las teorías lingüísticas como fundamento de los enfoques y métodos en la enseñanza de ELE». En Teoría y metodología para la enseñanza de ELE, I, eds. María Martínez Atienza de Dios y Alfonso Zamorano Aguilar. Madrid: En Clave-ele, pp. 39-66.

Gómez Capuz, Juan. 2001. Anglicismos léxicos en el español coloquial. Cádiz: Universidad de Cádiz, Servicio de Publicaciones.

Gómez Devís, M. ${ }^{\mathrm{a}}$ Begoña. 2003. La disponibilidad léxica de los estudiantes preuniversitarios valencianos: reflexión metodológica, análisis sociolingüístico y aplicaciones. Tesis Doctoral, Universidad de Valencia.

Gómez Molina, José Ramón. 1997. «El léxico y su didáctica: una propuesta metodológica». REALE: Revista de Estudios de Adquisición de la Lengua Española, 7: 69-94.

Hernández Navarro, Miguel Ángel. 2019. Aquí y ahora: diario de escritura. Madrid: Fórcola.

Higueras, Marta. 2017. «Logros y retos de la enseñanza del léxico». En Enseñar léxico en el aula de español, VV.AA. Barcelona: Difusión, pp.12-19.

Laval, Christian y Pierre Darcot. 2009. La nouvelle raison du monde. Paris: Éditions La Découverte.

Lewis, Michael. 1993. The Lexical Approach: The State of ELT and Way Forward. Hove: Language Teaching Publications.

—. 2000. Teaching Collocation: Further Developments in the Lexical Approach. Hove: Language Teaching Publicatons.

Lorenzo, Emilio.1996. Anglicismos hispánicos. Madrid: Gredos.

Martín Peris, Ernesto et al. 2008. Diccionario de términos clave de ELE. Madrid: SGEL e Instituto Cervantes.

Martínez Egido, José Joaquín. 2009. «El léxico del español de los negocios: propuesta de análisis para su enseñanza y aprendizaje». En Investigaciones lingüísticas en el siglo XXI, eds. Juan Luis Jiménez Ruiz y Larissa Timofeeva. Alicante: Universidad de Alicante, pp.169-187.

Medina López, Javier. 2004. El anglicismo en el español actual. Madrid: Arco/Libros.

RAE y ASELE, 2009: Nueva gramática de la lengua española. Madrid: Espasa.

Rodríguez Gallardo, Ángel. 2013 «Léxico de la crisis. Medios de comunicación y propaganda económica». Les Cahiers du Geres, 6: 62-78.

—. 2016. «Lexico y retórica argumentativa de la crisis económica». En Estudios sobre el léxico. Puntos y contrapuntos, ed. Aura Luz Duffé Montalván. Berna: Peter Lang, pp. 65-105.

Romero Gualda, M. ${ }^{a}$ Victoria. 1993. El español en los medios de comunicación. Madrid: Arco/Libros.

Soler-Espiauba, Dolores. 2015. Contenidos culturales en la enseñanza del español como 2/L. 2. a edición. Madrid: Arco/Libros.

Ullman, Stephen. 1965. Semántica. Madrid: Aguilar. 
Vidiella Andreu, Mercè. 2012 El enfoque léxico en los manuales de ELE. Suplementos MarcoELE, 14. https://marcoele.com/descargas/14/vidiella-lexico.pdf

Vila Rubio, Neus. 2001. «El léxico económico: prensa y diccionarios». En Las lenguas de especialidad y su didáctica, VV.AA. Tarragona: Universitat Rovira i Virgili, pp. 317-327.

ANEXO 1. ÍNDICE DE LIBROS DE ECONOMÍA UTILIZADOS EN EL TRABAJO (CITADOS POR ORDEN ALFABÉTICO DEL AUTOR)

Abadía, Leopoldo. 2012. ¿Qué hace una persona como tú en una crisis como esta? Barcelona: Booket.

Ajram, Josef. 2011. Ganar en la bolsa es posible. Barcelona: Plataforma Editorial.

Alonso, Mario. 2012. Madera de líder. Barcelona: Empresa Activa.

Álvarez de Mon, Ignacio. 2016. Emprendedores solidarios. Madrid: Lid Editorial.

Arqués, Neus. 2019. Y tú, ¿qué marca eres? Barcelona: Alienta Editorial.

Becerra, Beatriz. 2018. Eres liberal y no lo sabes. Barcelona: Deusto.

Bermejo, Pedro. 2014. Neuroeconomía. Cómo piensan las empresas. Madrid: Lid Editorial.

Bernstein, William. 2016. Los cuatro pilares de la inversión. Barcelona: Deusto.

Blanco, María. 2014. Las tribus liberales. Barcelona: Deusto.

Bogle, John C. 2017. Cómo invertir en fondos de inversión. Barcelona: Deusto.

Carrillo, Fran, coord. 2017. El porqué de los populismos. Barcelona: Deusto.

Cerejido, Inmaculada. 2012. Desmotivados = improductivos (Las verdaderas razones de la falta de productividad). Barcelona: Empresa Activa.

Corral, Cristina. 2018. Destino emprender: el camino de dejar un trabajo seguro para aventurarse al emprendimiento. Madrid: Vive Hoy.

Crespo, Juan Ignacio. 2012. Las dos próximas recesiones. Barcelona: Deusto.

- 2014. Cómo acabar de una vez por todas con los mercados. Barcelona: Deusto.

—. 2016. ¿Por qué en 2017 volveremos a entrar en recesión? Barcelona: Deusto.

Cubeiro, Juan Carlos. 2012. Del capitalismo al talentismo: claves para triunfar en la nueva era. Barcelona: Deusto.

Cubeiro, Juan Carlos y Leonor Gallardo. 2008. Liderazgo, empresa y deporte. Madrid: Lid Editorial.

De la Corte, Jesús y Fernando Lallana. 2019. Sorbos de emprendimiento: sentir y pesar un proyecto de éxito. Barcelona: Plataforma Editorial.

Delgado, Carla. 2014. El emprendedor digital: herramientas para triunfar en el mundo virtual con poco dinero. Barcelona: Plataforma Editorial.

Delgado, Juan Francisco. 2016. ¿Te atreves a innovar? Cómo emprender y no morir en el intento. Barcelona: Institut de Ciencies Politiques i Socials.

Díaz, Alexis. 2016. ¡Hoy voy a emprender! Barcelona: Profit Editorial

Díaz, Viviana. 2018. Teletrabajo y neurotecnología. Buenos Aires: Ediciones Granica.

Economistas Aterrados. 2012. La espiral de la austeridad. Madrid: Pasos Perdidos.

Estay, Christian A. 2009. Las TIC en la empresa turística. Barcelona: Fundación Universitaria Iberoamericana.

Faustino, Ángel. 2015. Invertir tus ahorros y multiplicar tu dinero. Barcelona: Planeta 
Fernández, Javier. 2019. Liderar en un mundo imperfecto. Madrid: Lid Editorial.

Fernández, Sergio y Raimon Samsó. 2017. Misión emprender: los 70 hábitos de los emprendedores de éxito. Barcelona: Conecta.

Fernández-Cruz Sequera, Francisco José. 2015. Crónicas del austericidio, Madrid: EAS.

Ferrer López, Miguel Ángel. 2019. Nóminas y seguros sociales 2019. Barcelona: Deusto.

Fitz-Enz, Jac. 2007. El ROI (rendimiento de la inversión) del capital humano. Barcelona: Deusto.

Freire, Bartolomé. 2017. La jubilación. Madrid: Lid Editorial.

Freire, Espido. 2006. Mileuristas: retrato de la generación de los mil euros. Barcelona: Ariel.

García, Javier y Enrique González. 2017. La burbuja emprendedora. Barcelona: Empresa Activa.

Garicano, Luis. 2019. El contrataque liberal. Barcelona: Planeta.

Gómez Sinde, Araceli. 1983. Todo sobre el cheque bancario. Barcelona: De Vecchi.

Grañó, Marta. 2016. Crea tu propia empresa. Barcelona: Profit Editorial.

Greenblatt, Joel. 2016. El pequeño libro que aún vence al mercado. Barcelona: Deusto.

Hasson, Gill. 2015. Mindfulness eficaz. Madrid: Empresa Activa.

Ilie, Camelia y María José Martín. 2011. El ADN de la formación para directivos. Madrid: Lid Editorial.

Judis, John B. 2018. La explosión populista. Barcelona: Deusto.

Kaiser, Axel y Gloria Álvarez. 2016. El engaño populista. Barcelona: Deusto.

Lacalle, D. 2017. Inflación, paro y productividad. El caso español y europeo. Barcelona: Fundación Universitaria Española.

—. 2014. Nosotros, los mercados. Qué son, cómo funcionan y por qué resultan imprescindibles. Barcelona: Deusto.

—. 2017. Viaje a la libertad económica. Barcelona: Booket.

Lázaro, María. 2019. Community Manager. La guía definitiva. Madrid: Anaya.

López, Salvador. 2011. Rock-volución empresarial. Barcelona: Empresa Activa.

López, Vicente. 2018. ;Maldita hipoteca! Independently published

Losada, Antón. 2013. Piratas de lo público: el neoliberalismo corsario al abordaje del estado del bienestar. Barcelona: Deusto.

Massons, Joan. 2015. Finanzas para profesionales de marketing y ventas. Barcelona: Deusto.

Molins, Jordi. 2014. Confidencias de un especulador. Barcelona: Deusto.

Mondéjar, Daniel. 2012. Libertad de emprender. Madrid: Lid Editorial.

Muro, Paco. 2018. G.E.R. Gestión Eficaz de Recompensas. Barcelona: Empresa Activa.

Murphy, John J. 2016. Análisis técnico de los mercados financieros. Barcelona: Gestión 2000

Nadal, Álvaro. 2019. Lo que no son cuentas son cuentos. Barcelona: Deusto.

Nieto, Luis Fidel. 2012. De mileurista a millonario. Autoedición.

Nivón, Eduardo y Ana Rosas Mantecón, coords. 2010. Gestionar el patrimonio en tiempos de globalización. México: Universidad Autónoma Metropolitana. 
Nueno, Pedro. 2019. Emprendimiento hacia el 2020: una renovada perspectiva global del arte de crear empresas y sus artistas. Barcelona: Deusto.

Osterwalder, Alexander. 2013. Tu modelo de negocio. Barcelona: Deusto.

Ovejero, Anastasio. 2017. Autogestión para tiempos de crisis. Madrid: Biblioteca Nueva

Palacios, Mario Italo. 2018. El emprendedor, o los accionistas, crean empresas para producir ganancias, nunca para perder dinero. Michigan: Independently published

Parize, Bruno Dureux. 2019. Cómo gestionar una PYME y no morir en el intento. Michigan: Independently published.

Penaloza, Miguel y Tomás Penaloza. 2019. La desaceleración económica: las causas e implicaciones en los países desarrollados. Michigan. Independently published

Peralba, Raúl y Ralp Whitestone. 2012. El principio «Kicks» (Keep It Competitive, Stupid). Barcelona: Empresa Activa.

Prada, Albino. 2019. Crítica del hipercapitalismo digital. Madrid: Los Libros de la Catarata.

Rallo, Juan Ramón. 2012. Un modelo realmente liberal. Madrid: Lid Editorial.

Ries, Eric. 2012. El método Lean Startup. Barcelona: Deusto.

Rodríguez, Carlos. y Juan Ramón Rallo. 2011. El liberalismo no es pecado. Barcelona: Deusto.

Romano, Jaime. 2012. Neuropirámide, base del neuromarketing. Madrid: Lid Editorial. Rosell, Juan. 2013. Reformas o declive. Barcelona: Deusto.

Rottenberg, Linda. 2016. Loco por emprender: desafía las normas convencionales. Madrid: Aguilar.

Ruiz, Ricardo J. 2014, Cómo entender los tipos de interés. Madrid: Paraninfo

Sáez, Nuria y Julián Trullén. 2012. Ya eres líder. Madrid: Lid Editorial.

Sevilla, Jordi. 2012. Economía en dos tardes: un manual para todos, incluidos presidentes del Gobierno. Barcelona: Deusto.

Shiller, Robert J. 2012. Las finanzas en una sociedad justa. Barcelona: Deusto.

Solsona, Jordi. 2017. Riqueza y bolsa para mileuristas: cómo alcanzar la libertad financiera mejorando tu economía. CreateSpace Independent Publishing Platform.

Tormo, Eduardo. 2013. Crecer en franquicia. Barcelona: Gestión 2000

Torres, Juan. 2016. Economía para no dejarse engañar por economistas. Barcelona: Deusto.

Trías de Bes, Fernando. 2007. El libro negro del emprendedor: no digas que nunca te lo advirtieron. Barcelona: Empresa Activa.

Velasco, Mariano y Edmundo Perroni. 2019. La revalorización de las pequeñas y medianas empresas desde lo local. Madrid: EAE.

VV.AA. 2017. El euro y la batalla de las ideas. Barcelona: Deusto.

VV.AA. 2017. El libro de los emprendedores. Barcelona: Deusto.

VV.AA. 2019. Reglamento del registro mercantil. Barcelona. Linkgua

Weinstein, Stan. 2014. Secretos para ganar en los mercados alcistas y bajistas. Barcelona: Valor Editions. 